\title{
Therapeutic Potential and Effective Components of the Chinese Herb Gardeniae Fructus in the Treatment of Senile Disease
}

\author{
Shichao Lv², Yang Ding ${ }^{3}$, Haiping Zhao ${ }^{4}$, Shihao Liu5, Junping Zhang 2, *, Jun Wang ${ }^{1, ~ * ~}$ \\ ${ }^{1}$ Institute of Basic Theory, China Academy of Chinese Medical Sciences, Beijing, China \\ ${ }^{2}$ Department of Geriatric Medicine, First Teaching Hospital of Tianjin University of Traditional Chinese \\ Medicine, Tianjin, China \\ ${ }^{3}$ Digestive Disease Center, Beijing Hospital of Traditional Chinese Medicine Affiliated to Capital Medical \\ University, Beijing, China \\ ${ }^{4}$ Cerebrovascular Diseases Research Institute, Xuanwu Hospital of Capital Medical University, Beijing, China \\ ${ }^{5}$ Department of Cell and Developmental Biology, School of Molecular and Cellular Biology, University of \\ Illinois at Urbana-Champaign, USA
}

[Received May 18, 2017; Revised September 4, 2017; Accepted January 12, 2018]

\begin{abstract}
Gardeniae fructus (GF), an evergreen Rubiaceae shrub, is one of the most commonly used Chinese herbs in traditional Chinese medicine (TCM) and has been used for over a thousand years. It is usually prescribed for the treatment of brain aging, vascular aging, bone and joint aging, and other age-related diseases. It has been demonstrated that several effective compounds of GF, such as geniposide, genipin and crocin, have neuroprotective or related activities which are involved in senile disease treatment. These bioactivities include the mitochondrion dysfunction, antioxidative activity, apoptosis regulation and an anti-inflammatory activity, which related to multiple signaling pathways such as the nuclear factor- $\mathrm{KB}$ pathway, AMP-activated protein kinase signaling pathway, and the mitogen-activated protein kinase pathway. To lay the ground for fully elucidating the potential mechanisms of GF in treating age-related pathologies, we summarized the available research conducted in the last fifteen years about GF and its effective components, which have been studied in vivo and in vitro
\end{abstract}

Key words: age-related diseases, gardenia, geniposide, mechanism, Senile Disease, Chinese Herb

The lifespan of human beings has been prolonged with the modernization and development of medical progress. In the last century, developed countries have benefited from medical advances, improvements in public healthcare systems and better living conditions derived from their socioeconomic power, which have helped achieve a marked increase in life expectancy [1]. However, age- related diseases are still a big challenge for us. Aging is a long, gradual process of functional decline which may not necessarily result in diseases that need to be treated [2]. The number of people suffering from age-related diseases is anticipated to almost double over the next two decades [3]. According to the China Aging Development Report (2013), the severity of the aging population in China is

*Correspondence should be addressed to: Dr. Jun Wang, China Academy of Chinese Medical Science, Beijing, China. Email: Maggie.wj@126.com; or Dr. Junping Zhang, First Teaching Hospital of Tianjin University of Traditional Chinese Medicine, Tianjin, China. Email: tjzhtem@163.com.

Copyright: () 2018 Lv S et al. This is an open-access article distributed under the terms of the Creative Commons Attribution License, which permits unrestricted use, distribution, and reproduction in any medium, provided the original author and source are credited. 
rarely seen elsewhere in the world. By 2030, China's aging population (aged 60 and above) is expected to reach 400 million, which is almost equivalent to the total population of $15 \mathrm{EU}$ countries [4].

According to the systemic theory, aging is associated with a decline in the function of essential organ systems [5]. Many physiological and pathological mechanisms are involved in the aging process. The free radical theory of aging postulates that the production of intracellular reactive oxygen species (ROS) is the major determinant of lifespan [6]. Mitochondrial dysfunction is the central in the aging theories, as age-related changes in mitochondria are likely to impair a host of cellular physiological functions in parallel and contribute to the development of all common age-related diseases [7]. A defect in mitochondrial respiratory enzymes can increase mitochondrial production of ROS, causing further mitochondrial damage, leading to a further decline in cellular and organ function that can eventually progress to death [8]. Several important pro-inflammatory mediators, such as nuclear factor- $\mathrm{kB}$ (NF- $\kappa \mathrm{B})$, inducible nitric oxide synthase and cyclooxygenase, are known to increase ROS production, which leads to DNA and tissue damage and thus results in age-related disease [9]. Low-grade inflammation is also a hallmark of aging, and the systemic level of inflammation is negatively correlated with human longevity [10]. Recent investigations revealed a link between autophagy and aging in yeast, most notably because autophagy genes are required for TOR inhibition to extend chronological lifespan [11, 12], and because spermidine, a pharmacological activator of autophagy, increases lifespan via an autophagy-dependent mechanism [13].

Many Chinese herbs have antiaging properties and could intervene aging-associated disorders such as Ginseng, Huangqi and Herba Cistanches, et al [14-16]. The Chinese herb Gardeniae fructus (GF) is an evergreen Rubiaceae shrub, which is widely used in Asian countries as a complementary and alternative therapy. As a kind of traditional Chinese medicine with the effect of clearing heat and detoxifying, GF has been used in traditional Chinese medicine (TCM) due to the homeostatic, antiphlogistic, analgesic and antipyretic effects [17]. Like other Chinese herbs with clearing heat and detoxifying effects such as Rhizoma Coptidis and Baicalin [18-19], GF also has antiaging effect. The main components of GF include geniposide and crocin [20] which exhibit antioxidant, anti-inflammatory and hypolipidemic activities [21-23]. Several important pathologies and pathways related to aging, such as oxidative stress, mitochondrial malfunction, and mTOR signaling pathways were confirmed to be regulated by GF or its components, particularly geniposide [24-26]. Thus, we regard GF as a promising candidate for the prevention and treatment of aging and age-associated disorders by targeting multiple age-associated signaling pathways. In this review, we aim to summarize the possible mechanisms and pathways related to the anti-aging activity of GF and its components in combating agerelated diseases.
A

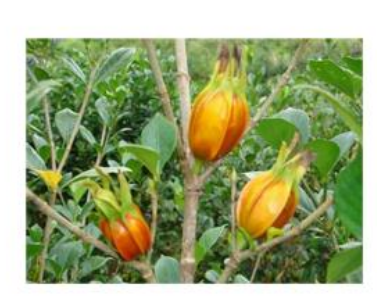

$B$

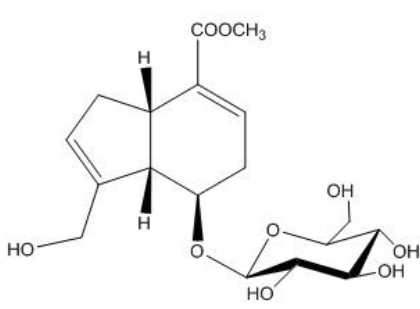

D

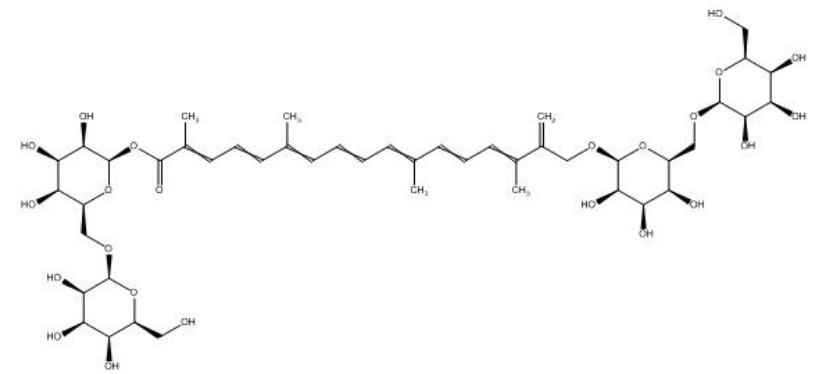

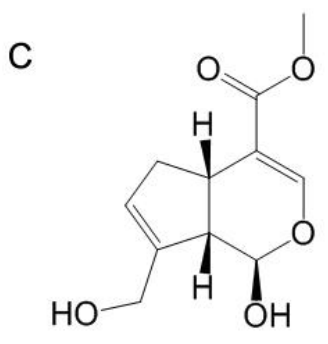

$$
\text { HO }
$$

$\mathrm{OH}$ 


\section{Modern pharmacological research on the main constituents of gardenia}

\subsection{A general overview of gardenia and its bioactive components.}

Gardeniae fructus (Fig. 1A; Chinese herbal name: Zhizi), is firstly recorded in the book named 'Shen Nong's Herbal Classic', and is mainly distributed in tropical zones and subtropical regions of China. Flora of China pointed out that there were seven types of Gardenia plants in China: Zhizi (G. J. E.), Hainan Zhizi (G. Hananensis Merr.), Xiaye Zhizi (G. stenophylla Merr.), Shiye Zhizi (G. angkorensis Pitard), and Dahuang Zhizi (G. sootepensis Hutchins.) with two varieties (Baichan Zhizi, or Chongban Zhizi, G. jasminoides Ellis var. fortuniana (Lindl.) Hara and G. jasminoides var. jasminoides) [27]. Among the different species of the Gardenia genus, the mainstream species is Zhizi $(G . J . E$.) which is usually used for medicine in China [28]. Some scholars used crocin, an effective component of Gardenia, to observe the differences in the effective components among these species. The results showed that the species was not the only factor that affected the content of the effective components; the storage conditions also had an influence. Prolonged storage time, light or high temperature could decrease the contents of effective components [28]. A number of new iridoid glycosides have been identified, which are major bioactive constituents, such as geniposide, genipin, geniposidic acid, crocetin and genipin-1- $\beta$-D-gentiobioside [29]. Geniposide (Fig. 1B) is a major iridoid compound present in G. jasminoides fruits, and genipin, an aglycone of geniposide, is the only iridoid aglycone commercially available in relatively large amounts. Geniposide is hydrolyzed to the aglycone genipin by h-D-glucosidases in the intestine and the liver [30]. Genipin (Fig. 1C) has a molecular weight of 226 and a white crystalline structure. It is soluble in ethanol and ethyl acetate and slightly soluble in water [31]. Genipin generates both color and fluorescence in a single reaction with biopolymers containing primary amine groups. The reaction between genipin and collagen induces the formation of cyclic structures, which serve as the intramolecular and intermolecular crosslinks between collagen molecules within fibers [32]. Crocin (Fig. 1D), a 8,8'diapo-8,8'-carotenic acid, belongs to the carotenoid family. It is characterized by a diterpenic and symmetrical structure with alternating double bonds and four methyl groups, and is slightly soluble in water [33]. Crocin is a part of the group of hydrophilic carotenoids with either mono- or di-glycosyl polyene esters of crocetin with Dglucose and/or D-gentiobiose as carbohydrate residues [34]. A variety of traditional Chinese herbal preparations contain GF, such as Longdan Xiegan Pill [35],
Yinchenhao Decoction [36], or Zhizichi Decoction [37]. In the traditional Chinese patent medicine, GF has been used as an ingredient in Huanglian Jiedu Decoction [38], Tongluo Jiunao Injection [39], and Xingnaojing Injection [40].

\subsection{Pharmacokinetic profile}

The pharmacokinetic profile of GF bioactive components such as geniposide or genipin has been well studied in humans and animals. Geniposide is a water-soluble iridoid glycoside component found in GF, but geniposide itself is not regarded as a major active ingredient of GF extracts [41]. Geniposide has been shown to be hydrolyzed by $\beta$-D-glucosidases into genipin in the intestine. Genipin is liposoluble, and this property enables genipin to easily permeate into intestinal mucosa and facilitates absorption. It was found that intestinal bacteria in animals could transform geniposide to its aglycone genipin [30]. Some studies have shown that after oral administration of genipin or GF contained decoction, genipin sulfate is a major metabolite in the bloodstream, whereas the precursor forms of genipin and geniposide were not detected [42]. When used in combination with other herbs, the absorption of geniposide could change. Berberine may not affect the absorption of geniposide, whereas baicalin increase the absorption of geniposide. In addition, the function of berberine is to inhibit the positive effect of baicalin on geniposide uptake in the body [43]. The absolute bioavailability of geniposide was $76.14 \%$ following intranasal administration combined with natural borneol. Compared with the intranasal administration of geniposide alone, geniposide can be absorbed rapidly in the nasal cavity combined with natural borneol [44]. In various physiological or pathological animal models, the effects of geniposide absorption also varied greatly. Specifically, the effects of geniposide absorption in middle cerebral artery occlusion injured rats were better than in normal rats [43] (Table 1).

\section{The anti-aging effect of Gardenia and its components}

\subsection{Brain aging}

\section{Alzheimer's disease}

Alzheimer's disease (AD), characterized by memory deficits and cognitive decline, is a progressive neurodegenerative disorder. In an AD mouse model, geniposide ameliorated cognitive defects in middle-aged mice [45]. Lv et al. reported that treatment with geniposide suppressed RAGE-dependent signaling, the production of interleukin (IL)-1 $\beta$ and tumor necrosis 
factor- $\alpha$ and cerebral $A \beta$ accumulation in an $\mathrm{AD}$ mouse model. Geniposide improved learning and memory in model mice [46]. Geniposide trafficked in cultured hippocampal neurons and improved mitochondrial motility, alleviated $A \beta$-induced axonal mitochondrial abnormalities by increasing axonal mitochondrial density and length. In neurons and APPswe/PS1dE9 mice, decreases in synapse-related proteins were ameliorated by geniposide [47]. A study in APP/PS transgenic AD mice showed that the leptin antagonist influenced the expression of secretases and the activities of leptin signaling molecules associated with the production of $A \beta$ $1-42$. Geniposide may regulate the production of $A \beta 1-$
42 via leptin signaling [48]. In AD transgenic mouse model, geniposide at the concentrations of $2.5,5$ and 10 $\mu \mathrm{M}$ protected cultured primary cortical neurons from $\mathrm{A} \beta$ mediated mitochondrial dysfunction in a dose-dependent manner by recovering mitochondrial membrane potential, promoting ATP generation and increasing cytochrome $\mathrm{c}$ oxidase and caspase $3 / 9$ activity by reducing cytochrome c leakage and ROS production, and by inhibiting apoptosis [49]. In an insulin-deficient APP/PS1 transgenic mouse model, geniposide enhanced the role of insulin on the phosphorylation of GSK-3b, Akt and tau in primary cultured cortical neurons [50].

Table 1. The anti-aging effects of gardenia and its components.

\begin{tabular}{|c|c|c|c|c|}
\hline Model & Tissue & Mechanisms & Bioactive component & Ref. \\
\hline Mice & Brain & $\begin{array}{l}\text { MAPK signaling pathway } \downarrow \\
\text { ChAT } \uparrow, \text { AChE } \downarrow\end{array}$ & Geniposide & {$[62]$} \\
\hline Mice & Brain & $\begin{array}{l}\text { RAGE-dependent signaling, TNF- } \alpha \text {, IL- } 1 \beta \\
\text { and cerebral } A \beta \text { accumulation } \downarrow\end{array}$ & Geniposide & {$[46]$} \\
\hline APPswe/PS1dE9 mice & Brain & $\begin{array}{l}\text { Increase axonal mitochondrial density and } \\
\text { length }\end{array}$ & Geniposide & [47] \\
\hline $\begin{array}{l}\mathrm{APP} / \mathrm{PS} \text { transgenic } \mathrm{AD} \\
\text { mice }\end{array}$ & Brain & $\begin{array}{l}\text { Induce the phosphorylation of JAK2 and } \\
\text { STAT3 }\end{array}$ & Geniposide & {$[48]$} \\
\hline $\begin{array}{l}\text { Insulin-deficient APP/PS1 } \\
\text { transgenic mouse }\end{array}$ & Brain & $\begin{array}{l}\text { The phosphorylation of GSK- } 3 \beta \uparrow \\
\text { The phosphorylated level of tau } \downarrow\end{array}$ & Geniposide & [49] \\
\hline $\begin{array}{l}\text { The MPTP mouse model } \\
\text { of PD }\end{array}$ & Brain & $\begin{array}{l}\operatorname{Bcl}-2 \downarrow \\
\operatorname{Bax} \uparrow\end{array}$ & Geniposide & {$[51]$} \\
\hline PD mouse & Brain & $\begin{array}{l}\text { Block microRNA-21/lysosome-associated } \\
\text { membrane protein } 2 \mathrm{~A} \text { interaction }\end{array}$ & Geniposide & {$[52]$} \\
\hline $\begin{array}{l}\text { Spontaneously } \\
\text { Hypertensive rats }\end{array}$ & kidney & $\begin{array}{l}\text { blood pressure, serum creatinine, blood urea } \\
\text { nitrogen, cell proliferation, ROS generation } \downarrow\end{array}$ & Genipin & {$[56]$} \\
\hline C57/B6 mice & Heart & $\begin{array}{l}\text { AMPK } \alpha \uparrow \\
\text { mammalian target of rapamycin, ERK and } \\
\text { endoplasmic reticulum stress } \downarrow\end{array}$ & Geniposide & [57] \\
\hline Rabbit & Artery & $\begin{array}{l}\text { ECs shedding, the plaque area, intima/media } \\
\text { thickness ratio, intimal foam cells number } \downarrow\end{array}$ & Geniposidic acid & {$[58]$} \\
\hline Mouse and rat & Artery & $\begin{array}{l}\text { length of tail thrombus, platelet aggregation, } \\
\text { venous thrombosis } \downarrow\end{array}$ & $\begin{array}{l}\text { GJ-ext、Geniposide } \\
\text { and genipin }\end{array}$ & {$[60[$} \\
\hline Aging rat & Liver & $\begin{array}{l}\text { cellular ROS overproduction, MMP, ATP, Akt } \\
\text { phosphorylation } \downarrow \\
\text { glucose consumption, glycogen synthesis } \uparrow\end{array}$ & Genipin & [73] \\
\hline $\begin{array}{l}\text { Collagen-induced arthritis } \\
\text { rats }\end{array}$ & Joint & 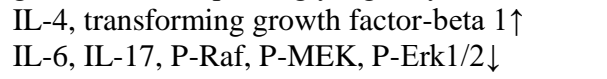 & Geniposide & {$[68]$} \\
\hline Rat & Ankle joint & Swelling ratio $\downarrow$ & Geniposide & [72] \\
\hline
\end{tabular}

Note: Treg, regulatory T; p-JNK, phospho-JNK; IL-6, interleukin 6; AchE, acetylcholin esterase; TNF, tumor necrosis factor;MPTP, 1-Methyl4-phenyl-1,2,3,6-tetrahydropyridine; LDL-c: low-density lipoprotein cholesterol; AMPK $\alpha, 5$ '-AMP-activated protein kinase- $\alpha$; ECs, endothelial cells; GJ-ext, extract of G. jasminoides; SOD, superoxide dismutase; NOS, nitric oxide synthase; fgf, Fibroblast growth factor; PXN, paxillin; ROS, reactive oxygen species; MMP, mitochondrial membrane potential; ATP, adenosine tri-phosphate.

\section{Parkinson's disease}

The neuroprotective effects of geniposide were also studied in the MPTP mouse model of Parkinson's disease (PD). After MPTP treatment, geniposide was administered $(100 \mathrm{mg} / \mathrm{kg}$ intraperitoneal) for 8 days. Geniposide treatment reduced the apoptosis signaling molecule Bcl-2 and increased the levels of growth factor signaling molecule Bax [51]. Geniposide also reduced $\alpha$ synuclein by blocking the microRNA-21/lysosome- 
associated membrane protein $2 \mathrm{~A}$ interaction in PD models [52].

\subsection{Vascular aging effect}

\section{Cardiovascular aging}

Gardenia and its components, especially geniposide, possess unique pharmacological activities in cardiovascular disorders. Initial studies about the atherosclerosis treatment with GF showed that gardenia inhibited the development of atherosclerosis in ApoEknockout mice. Geniposide inhibited dickkopf-related protein-1 and increased Wnt1 expression, while upregulating the expression of foxp3, decreasing the numbers of dendritic cells (DC), and inhibiting DC maturation and infiltration into lesions in bone marrow [53-55]. In hypoxia/reoxygenation injured $\mathrm{H} 9 \mathrm{c} 2$ cells, pretreatment with geniposide increased cell viability, decreased lactate dehydrogenase levels in the supernatant, and inhibited cardiomyocyte apoptosis caused by hypoxia/reperfusion. Furthermore, geniposide reversed mitochondrial dysfunction by decreasing oxidative stress products (reactive oxygen species/reactive mitrogen species and malondialdehyde) by increasing antioxidative enzyme level, improving mitochondrial morphology, attenuating mitochondrial calcium overload and blunting depolarization of the mitochondrial membrane [25]. In addition, geniposide at a range of $10-80 \mu \mathrm{M}$ improved H9c2 cell viability, with $40 \mu \mathrm{M}$ being the optimal dosage. Another study of spontaneously hypertensive rats suggested that genipin not only decreased blood pressure, but also improved renal function, as shown by decreased blood urea nitrogen and serum creatinine, as well as urinary microalbumin and N-acetyl- $\beta$-Dglucosaminidase [56]. In C57/B6 mice with transverse aorta constriction, geniposide inhibited the hypertrophic response induced by constriction of the transverse aorta or by isoprenaline. Activation of 5'-AMP-activated protein kinase- $\alpha$ (AMPK $\alpha)$ and inhibition of mammalian target of rapamycin, extracellular regulated protein kinases and endoplasmic reticulum stress were observed in hypertrophic hearts treated with geniposide [57]. In the atherosclerosis rabbit model, geniposidic acid improved the plaque area, intima/media thickness ratio, and intimal foam cell number [58]. Genipin inhibited TNF- $\alpha$-induced vascular smooth muscle cells proliferation and migration in a dose-dependent manner. Genipin prevented Akt phosphorylation and ERK/ mitogen activated protein kinase (MAPK), while $\mathrm{c}$ - Jun $\mathrm{N}$ - terminal kinase and $\mathrm{p} 38$ MAPK were unchanged [59]. The antithrombotic activities of the aqueous extracted geniposide were studied in mouse and rat models. Geniposide decreased the length of tail thrombus, improved thrombosis and inhibited platelet aggregation induced by thrombin/collagen [60]. In lipopolysaccharide (LPS)induced human umbilical vein endothelial cells (HUVECs), geniposide inhibited LPS-induced expression of IL-8 and IL- 6 at the translation and transcription levels. Additionally, geniposide suppressed the adhesion of U937 monocyte to HUVECs as well as LPS-induced HUVEC migration [61].

\section{Cerebrovascular aging}

In a study of chronic cerebral ischemia, geniposide protected the brain from injury and improved learning and memory [62]. In addition, in the in vitro model of cerebral ischemia induced by oxygen-glucose-deprivation (OGD) in brain microvascular endothelial cells (BMEC), the results showed that geniposide decreased the production of monocyte chemotactic protein 1 , IL- 8 and IL-1 $\beta$, and downregulated the expression of $\mathrm{P} 2 \mathrm{Y} 14$ receptor and the downstream ERK1/2 signaling pathway [63]. Geniposide displayed a neuroprotective effect on ischemia/ reperfusion-injured rats in vivo and inhibited OGDinduced activation of microglial cells by attenuating inflammatory factors and nuclear factor- $\mathrm{B}$ (NF- $\mathrm{B}$ ) activation in vitro [64]. In the mouse model of brain damage induced by focal cerebral ischemia/reperfusion, jasminoidin and ursodeoxycholic acid were used to treat focal cerebral ischemia and reperfusion injury, which was characterized by the expression of the gene Hspala, genes Fgf12, Rara, and Map3k4 were up-regulated and gene $P X N$ was down-regulated, and the p53 pathway was activated [65]. In deprivation-exposed hippocampal slices cultured with damaged neuronal cells, neuronal cell death of both the granular cell layer (dendate gyrus region) and the pyramidal (CA 1 plus 3 region) region was ameliorated by 10,50 and $100 \mu \mathrm{M}$ geniposide in a dosedependent manner [66] (Table 2).

\subsection{Bone and joint aging}

Chronic arthritis and osteoporosis are becoming serious issues in our aging society. GF has been used in the treatment of arthritis and related diseases. Geniposide could reduce the production of inflammatory cytokines and regulate immunity, which played critical roles in the treatment of arthritis $[67,68]$. In TCM, GF can be made into an extract to treat arthritis by external application to decrease the content of IL- $1 \beta$ and TNF- $\alpha$. Gardenia in combination with other Chinese herbs based on TCM theory could also have the therapeutic effect on arthritis [69]. In addition, geniposide was a useful drug for the treatment of postmenopausal osteoporosis as it inhibited c-Fos protein proteolysis and NF- $\mathrm{KB}$ activation [70]. Geniposide might also ameliorate ligament injuries and 
reduce the risk of degenerative joint disease [71, 72]. In addition, 25, 50, 100 and $200 \mu \mathrm{M}$ geniposide dosedependently improved cell survival.

Table 2. The function and mechanisms of the neuroprotective effects of geniposide.

\begin{tabular}{|c|c|c|c|c|}
\hline Disease & Cells/tissues & Effects & Mechanisms & Ref. \\
\hline \multirow{6}{*}{$\mathrm{AD}$} & Mice & $\begin{array}{l}\text { Enhance cholinergic } \\
\text { neurotransmission }\end{array}$ & $\begin{array}{l}\text { MAPK signaling pathway } \downarrow \\
\mathrm{ChAT} \uparrow, \mathrm{AChE} \downarrow\end{array}$ & {$[45]$} \\
\hline & Mice & Anti-inflammation & $\begin{array}{l}\text { RAGE-dependent signaling, TNF- } \alpha \text {, IL- } 1 \beta \\
\text { and cerebral } A \beta \text { accumulation } \downarrow\end{array}$ & [46] \\
\hline & APPswe/PS1dE9 mice & $\begin{array}{l}\text { Improve mitochondrial } \\
\text { motility }\end{array}$ & $\begin{array}{l}\text { Increase axonal mitochondrial density and } \\
\text { length }\end{array}$ & [47] \\
\hline & $\begin{array}{l}\text { APP/PS transgenic AD } \\
\text { mice }\end{array}$ & Regulate leptin signaling & $\begin{array}{l}\text { Induce the phosphorylation of JAK2 and } \\
\text { STAT3 }\end{array}$ & [48] \\
\hline & AD transgenic mouse & $\begin{array}{l}\text { Anti-apoptotic } \\
\text { Anti-oxidant }\end{array}$ & $\begin{array}{l}\text { Bcl- } 2 \uparrow \\
\text { Cytochrome c, caspase-9, caspase-3, Bax and } \\
\text { ROS } \downarrow\end{array}$ & [49] \\
\hline & $\begin{array}{l}\text { Insulin-deficient APP/PS1 } \\
\text { transgenic mouse }\end{array}$ & $\begin{array}{l}\text { Enhance insulin } \\
\text { signaling }\end{array}$ & $\begin{array}{l}\text { The phosphorylation of GSK- } 3 \beta \uparrow \\
\text { The phosphorylated level of tau } \downarrow\end{array}$ & {$[50]$} \\
\hline \multirow{2}{*}{ PD } & $\begin{array}{l}\text { The MPTP mouse model of } \\
\text { PD }\end{array}$ & Anti-apoptotic & $\begin{array}{l}\operatorname{Bcl}-2 \downarrow \\
\operatorname{Bax} \uparrow\end{array}$ & {$[51]$} \\
\hline & PD mouse & Reduce $\alpha$-synuclein & $\begin{array}{l}\text { Block microRNA-21/lysosome-associated } \\
\text { membrane protein } 2 \mathrm{~A} \text { interaction }\end{array}$ & {$[52]$} \\
\hline \multirow{3}{*}{$\begin{array}{l}\text { Cerebrovascular } \\
\text { aging }\end{array}$} & BMECs & Anti-inflammation & $\begin{array}{l}\text { The production of MCP- } 1, \text { IL- } 8 \text { and IL- } 1 \beta \downarrow \\
\text { Expression of } \mathrm{P} 2 \mathrm{Y}_{14} \text { receptor and ERK } 1 / 2 \\
\text { signaling pathway } \downarrow\end{array}$ & [53] \\
\hline & Microglial cells & Anti-inflammation & $\begin{array}{l}\text { Release of TNF- } \alpha \text {, IL- } 1 \beta \text {, IL- } 6 \text {, IL- } 8 \text { and IL- } \\
10 \downarrow \\
\text { NF- } \kappa B \text { activation } \downarrow\end{array}$ & [64] \\
\hline & Hippocampal slice & Neuroprotective effect & $\begin{array}{l}\text { Ameliorate the neuronal cell death of both } \\
\text { the granular and pyramidal cell layer }\end{array}$ & [66] \\
\hline
\end{tabular}

Note: AChE, acetylcholin esterase; NOS, nitric oxide synthase; SOD, superoxide dismutase; BMECs, brain microvascular endothelial cells; ERK1/2, extracellular signal-regulated kinase 1/2; MCAO, middle cerebral artery occlusion.

\subsection{Anti-aging effect in aging animals}

In natural-aging rats, hepatic tissues show steatosis and reduced glycogen content. Hepatic malondialdehyde level and mitochondrial ROS are higher, and mitochondrial membrane potential (MMP) and ATP level are lower compared with normal control rats. Administration of genipin ameliorated systemic and hepatic insulin resistance, hyperglyceridemia, hepatic steatosis, and alleviated hyperinsulinemia, and relieved hepatic oxidative stress and mitochondrial dysfunction in aging rats [73]. There is mounting evidence to show that changes occurring in the articular cartilage during the development of osteoarthritis are the result of an agerelated loss of normal homeostasis. The aging of chondrocytes appears to contribute to the loss of homeostasis [74]. Genipin preserved chondrocyte viability, which suggested that genipin had an anti-aging effect on chondrocytes [75]. In old rat hearts, treatment with genipin at the dose of $5-10 \mathrm{~mol} / \mathrm{L}$ for $15 \mathrm{~min}$ before prolonged ischemia exerted powerful antiradical and antilipoperoxidative activity [76].

\section{Mechanisms and key components of Gardenia's anti-aging effect}

\subsection{Mitochondrion mechanism}

Damaged mitochondria not only produce less ATP but also release greater numbers of ROS and have a higher propensity to induce apoptosis, and these phenomena are related to cardiac aging [77]. In A $\beta$-treated neurons and an $\mathrm{AD}$ mouse model, geniposide alleviated $\mathrm{A} \beta$-induced axonal mitochondrial abnormalities by increasing axonal mitochondrial density and length and improving mitochondrial motility and trafficking in cultured 
hippocampal neurons [47]. A study showed that geniposide reversed mitochondrial dysfunction by decreasing oxidative stress products, improving mitochondrial morphology, increasing anti-oxidative enzyme level, blunting depolarization of the mitochondrial membrane and attenuating mitochondrial calcium overload [25]. In the brains of AD patients, the accumulation of $A \beta$ is thought to be related to neuronal mitochondrial dysfunction. A study found that in $\mathrm{AD}$ transgenic mouse models, a pharmacologically active compound purified from gardenia, could reverse mitochondrial dysfunction and oxidative stress [49]. When neurons were cultured in ischemia-injured BMECs conditioned media, geniposide decreased cytochrome c release and increased MMP, which suggested a recovery of mitochondrial function [78].

\subsection{Anti-oxidant activity}

There was evidence that $\mathrm{SOD}^{+/-}$mice showed a clear increase in ROS load, but had a normal lifespan [79]. Reactive oxygen species accumulate over time and are the main contributor to the aging process [6]. Gardeniae fructus extract-capped gold nanoparticles effectively attenuated the increase in lysosome content and ROS production, and protected ARPE19 cells from hydrogen peroxide-induced premature senescence [80]. In ischemic brain injury, geniposide exhibited neuroprotective activity by preventing oxygen free radicals, improving the content of SOD, inhibiting nitric oxide synthase and anticholinesterase (AChE) activity and protecting neurons in the hippocampus CA1 and brain cortex [62]. When PC12 cells were exposed to hydrogen peroxide, geniposide enhanced the phosphorylation of Akt308, Akt473, GSK-3beta and PDK1 under conditions of oxidative stress [81]. In cancer treatment, the topical application of geniposide inhibited 12-0tetradecanoylphorbol-13-acetate (TPA)-induced edema in mice. Pretreatment of mouse skin with various amounts of geniposide caused inhibition of hydrogen peroxide and myeloperoxidase formation by TPA [78].

\subsection{Anti-inflammatory activity}

\section{$N F-\kappa B$ signaling}

Inflammation is the defensive response of living tissue in the vascular system to injury. Many studies have shown that Gardenia has anti-inflammatory activity in various diseases. Research on the treatment of arthritic diseases showed that geniposide inhibited colonic inflammation by decreasing the production of proinflammatory mediators, such as TNF- $\alpha$, IL-1 and IL- 6 , increasing the level of antiinflammatory cytokine IL-10 and inhibiting the phosphorylation of p38MAPK-related proteins. Notably, one study suggested that geniposide attenuated DKK1 expression and enhanced Wnt 1 signaling in cardiovascular disease, which may be associated with further inhibition of downstream cytokine expression and the inhibition of transcription factor NF- $\mathrm{kB}$ [55]. Geniposide could suppress the phosphorylation of inhibitory kappa B (I $\kappa \mathrm{B} \alpha), \mathrm{NF}-\kappa \mathrm{B}, \mathrm{p} 38$, ERK and JNK to downregulate the production of TNF- $\alpha$, IL- $1 \beta$ and IL- 6 in LPS-induced mastitis in mice [83].

\section{MAPK signaling}

The MAPK signaling pathway is involved in many inflammatory diseases. GF reduced IL-6, IL-12, TNF- $\alpha$ and interferon- $\gamma$ levels in mice with gastric injury, and mediated the p38MAPK signaling pathway in the regulation of damage and repair of the gastric mucosa epithelium [84]. In OGD-induced BMECs, geniposide inhibited the downstream ERK1/2 signaling pathways, and increased the release of proinflammatory cytokines IL-8, MCP-1 and IL-1 $\beta$, indicating that geniposide attenuated the inflammatory reaction through regulation of the MAPK signaling pathway. The MAPK signaling pathway is also essential in arthritic diseases, as shown by the inhibitions of proinflammatory cytokine IL- 6 and IL17 and decreased expression of p-Raf, p-MEK, and pErk1/2 levels by geniposide [68]. In genomics research, MAPK signaling pathway-related genes, such as $F g f 12$, Hspala, Rara, Map3k4 were found to be involved in the treatment effect of geniposide [65]. During the pathological process of atherosclerosis, genipin inhibited TNF- $\alpha$-induced VSMC migration and proliferation in a dose-dependent manner by preventing ERK/MAPK and Akt phosphorylation, while JNK and p38 MAPK were unchanged [59]. In addition, geniposide effectively inhibited LPS-induced expression of IL- 6 and IL-8 in HUVECs by blocking the activation of NF- $\kappa B$, degradation of $\mathrm{I} \kappa \mathrm{B} \alpha$, and phosphorylation of p38 MAPK and ERK1/2 in HUVECs challenged with LPS [61]. When microglial N9 cells were pre-treated with vehicle or geniposide and exposed to LPS, geniposide blocked the phosphorylation of p38 and ERK1/2, and inhibited the decrease in I $\mathrm{B} \mathrm{B} \alpha[85]$.

\section{AMPK signaling}

In digestive system diseases, AMPK activity has a role in epithelial barrier function. Geniposide attenuated LPSinduced epithelial barrier dysfunction by reducing proinflammatory cytokine release and activating the AMPK signaling pathway. Both AMPK siRNA transfection and AMPK overexpression abrogated geniposide-reduced myosin light chain kinase expression, 
suggesting that geniposide ameliorated barrier dysfunction via AMPK-mediated inhibition of the MLCK pathway [86]. Activation of glucagon-like peptide-1 (GLP-1) receptor exerts a range of cardioprotective effects. Geniposide is an agonist of the GLP-1 receptor. Activation of AMPK $\alpha$ and inhibition of the mammalian target of rapamycin, ERK and endoplasmic reticulum stress were observed in hypertrophic hearts treated with geniposide [57].

\subsection{Apoptosis regulation}

Genipin induced hepatoma cell apoptosis, which was mediated by ROS/c-Jun NH2-terminal kinase-dependent activation of the mitochondrial pathway [87]. In the antitumor mechanism, the activation of JNK may result in an increase in p53 protein level and lead to the mass accumulation of bax protein. Genipin-induced apoptosis was associated with activation of the c-Jun NH2-terminal kinase and p53 protein in HeLa cells [88]. Geniposide protected rat insulinoma cells from apoptosis in highglucose concentrations, and these effects were associated with an increased apoptosis-related Bcl-2/BAX protein ratio [89]. Geniposide effectively induced adjuvantinduced arthritis fibroblast-like synoviocyte apoptosis by regulating apoptosis-related gene expression, as shown by a decreased Bcl-2 mRNA level and increased Bax and caspase 3 mRNA levels [90]. $\beta$-Cell apoptosis is considered to be a major cause of $\beta$ cell loss in diabetes. Geniposide prevented oxidative stress-induced neuron apoptosis, and improved glucose stimulated insulin secretion by activating glucagon-likepeptide1 receptor (GLP-1R) in INS-1 cells [91]. Penta-acetyl geniposide transduced the apoptotic signals through PKC $\delta$ activation and the downstream cascades of JNK/Jun phosphorylation, FasL/Fas elevation, and the subsequent activation of caspase 8 and caspase $3[92,93]$.

\subsection{Regulation of glucose metabolism and lipid metabolism}

In diet-induced hyperlipidemic rats, a 10-day treatment with crocin significantly reduced serum triglycerides, total cholesterol, low density lipoprotein cholesterol and very low density lipoprotein cholesterol levels following a daily dose range of $25-100 \mathrm{mg} / \mathrm{kg}$, which demonstrated that crocin exerted its hypolipidemic effect by inhibiting pancreatic lipase, leading to malabsorption of fat and cholesterol [22]. In streptozotocin-induced diabetic rats, geniposide increased insulin serum level, decreased glucose level and affected the levels of total cholesterol and triglycerides [94]. Moreover, a study showed that GF improved insulin secretion and lowered plasma lipids in steroid-induced insulin resistant rats. Intracellular signaling proteins including peroxisome proliferatoractivated receptor and insulin receptor substrate-1 were elevated by GF $[96,96]$. It was shown that geniposide might be a potential drug for hypertriglycemia in diabetes. In addition, genipin, has been shown to alleviate agerelated insulin resistance, hyperinsulinemia, hyperglyceridemia and hepatic oxidative stress in aging rats [73]. Research on geniposide's regulation of hepatic glucose production in HepG2 cells showed that geniposide inhibited hepatic glucose production in a dosedependent manner. Different concentrations of geniposide stimulated AMPK, forkhead box class O1 phosphorylation and acetyl coenzyme A synthetase. In addition, the enzyme activities of glucose-6-phosphatase and phosphoenolpyruvate carboxykinase were suppressed by geniposide [97]. It has also been reported that the regulation of geniposide on diabetic cell adhesion and vascular injury might be related to its anti-oxidative activity and NF- $\mathrm{KB}$ signal pathway activation [98]. A clinical study showed that Gardenia intake with exercise had a positive effect on body composition and energy metabolism regulating hormones, characterized by the decrease of the visceral fat area in middle-aged obese women [99]. In estrogen-deficient rats, GF combined with Artemisia princeps Pamp and Leonurus japonicas Houtt exhibited increased hepatic peroxisome proliferatoractivated receptor- $\gamma$ coactivator- $1 \alpha$ expression, which increased the number of genes involved in fatty acid oxidation and decreased fatty acid synthesis. These results suggested that GF may have potential as a therapeutic agent in treating postmenopausal symptoms [100].

\section{Conclusions and Future Studies}

In this review, we summarized the therapeutic potential and effective components of the Chinese herb Gardeniae fructus in the treatment of age-related diseases. The antiaging properties of GF and its effective components are associated with inflammation, mitochondrial dysfunction and oxidative stress. Although the mechanisms of GF and its bioactive anti-aging components have been explored, there have been few studies examining the effects of GF and its bioactive components on central nervous system diseases. In addition, the main components of GF have a dose-dependent effect on anti-aging, but the potential side-effects of these components have not yet been fully studied. In addition to the longevity effects, many studies on GF and its effective components have been conducted to demonstrate their other health promoting properties, such as anti-cancer activity based on its anti-senescence effect. To the best of our knowledge, several experiments have shown the neuroprotective activities of GF in vitro but few studies have examined its effects in vivo. Over the last decade, there have been many studies investigating 
the therapeutic potential of GF and the use of its constituents as natural supplements for combating the aging process. Findings from these studies could lead to the development of GF preparations as new therapeutic agents for the treatment of age-related diseases.

\section{Acknowledgments}

This work was supported by Chinese Natural Science Foundation grants (81473449) and Beijing Natural Science Foundation (7164265).

\section{Conflict of Interest}

The authors have no conflict of interests in this paper.

\section{References}

[1] de Cabo R, Carmona-Gutierrez D, Bernier M, Hall MN, Madeo F (2014). The search for antiaging interventions: from elixirs to fasting regimens. Cell, 157:1515-26.

[2] Imai S (2010). A possibility of nutriceuticals as an antiaging intervention: activation of sirtuins by promoting mammalian NAD biosynthesis. Pharmacol Res, 62:427.

[3] Mercken EM, Carboneau BA, Krzysik-Walker SM, de Cabo R (2012). Of mice and men: the benefits of caloric restriction, exercise, and mimetics. Ageing Res Rev, 11:390-8.

[4] Sun R, Cao H, Zhu X, Liu JP, Dong E (2015). Current aging research in China. Protein Cell, 6:314-21.

[5] Weinert BT and Timiras PS (2003). Invited review: Theories of aging. J Appl Physiol (1985), 95:1706-16.

[6] Harman D (1956). Aging: a theory based on free radical and radiation chemistry. J Gerontol, 11:298-300.

[7] Dai DF, Rabinovitch PS, Ungvari Z (2012). Mitochondria and cardiovascular aging. Circ Res, 110:1109-24.

[8] Balaban RS, Nemoto S, Finkel T (2005). Mitochondria, oxidants, and aging. Cell, 120:483-95.

[9] $\quad \mathrm{Yu}$ BP and Chung HY (2001). Oxidative stress and vascular aging. Diabetes Res Clin Pract, 54 Suppl 2: S73-80.

[10] Youm YH, Grant RW, McCabe LR, Albarado DC, Nguyen KY, Ravussin A, et al. (2013). Canonical Nlrp3 inflammasome links systemic low-grade inflammation to functional decline in aging. Cell Metab, 18:519-32.

[11] Alvers AL, Wood MS, Hu D, Kaywell AC, Dunn WA, Jr., Aris JP (2009). Autophagy is required for extension of yeast chronological life span by rapamycin. Autophagy, 5:847-49.

[12] Matecic M, Smith DL, Pan X, Maqani N, Bekiranov S, Boeke JD, et al. (2010). A microarray-based genetic screen for yeast chronological aging factors. PLoS Genet, 6:e1000921.

[13] Eisenberg T, Knauer H, Schauer A, Buttner S, Ruckenstuhl C, Carmona-Gutierrez D, et al. (2009).
Induction of autophagy by spermidine promotes longevity. Nat Cell Biol, 11:1305-14.

[14] Yang Y, Ren CH, Zhang Y, Wu XD (2017). Ginseng: an nonnegligible natural remedy for healthy aging. Aging Dis, 8: 708-720.

[15] Liu P, Zhao HP, Luo YM (2017). Anti-aging implications of Astragalus Membranaceus (Huangqi): a well-known chinese tonic. Aging Dis, 8: 868-886.

[16] Wang NQ, Ji SZ, Zhang H, Mei SS, Qiao LM, Jin XL (2017). Herba Cistanches: anti-aging. Aging Dis, 8: 740-759.

[17] Jung WS, Chae YS, Kim DY, Seo SW, Park HJ, Bae GS, et al. (2008). Gardenia jasminoides protects against cerulein-induced acute pancreatitis. World J Gastroenterol, 14:6188-94.

[18] Liang W, Huang XB, Chen WQ (2017). The effects of Baicalin and Baicalein on cerebral ischemia: a review. Aging Dis, 8: 850-867.

[19] Xu ZF, Feng W, Shen Q, Yu NN, Yu K, Wang SJ, Chen ZG, Shioda S, Guo Y (2017). Rhizoma Coptidis and berberine as a natural drug to combat aging and agingrelated diseases via anti-oxidation and AMPK activation. Aging Dis, 8: 760-777.

[20] Hu Z, Wang Y, Luo G, He L (2005). [Estimation of measurement uncertainty of analytical results for the determination of three active components from Gardenia jasminoides Ellis. by HPLC]. Zhong Yao Cai, 28:991-4.

[21] Pham TQ, Cormier F, Farnworth E, Tong VH, Van Calsteren MR (2000). Antioxidant properties of crocin from Gardenia jasminoides Ellis and study of the reactions of crocin with linoleic acid and crocin with oxygen. J Agric Food Chem, 48:1455-61.

[22] Sheng L, Qian Z, Zheng S, Xi L (2006). Mechanism of hypolipidemic effect of crocin in rats: crocin inhibits pancreatic lipase. Eur J Pharmacol, 543:116-22.

[23] Oh PS and Lim KT (2006). Plant originated glycoprotein has anti-oxidative and anti-inflammatory effects on dextran sulfate sodium-induced colitis in mouse. J Biomed Sci, 13:549-60.

[24] Qi Q, Mao Y, Tian Y, Zhu K, Cha X, Wu M, et al. (2017). Geniposide inhibited endothelial-mesenchymal transition via the mTOR signaling pathway in a bleomycin-induced scleroderma mouse model. Am J Transl Res, 9:1025-36.

[25] Jiang YQ, Chang GL, Wang Y, Zhang DY, Cao L, Liu J (2016). Geniposide prevents hypoxia/reoxygenationinduced apoptosis in $\mathrm{H} 9 \mathrm{c} 2$ cells: improvement of mitochondrial dysfunction and activation of GLP-1R and the PI3K/AKT signaling pathway. Cell Physiol Biochem, 39:407-21.

[26] Wang J, Miao M, Qu L, Cui Y, Zhang Y (2016). Protective effects of geniposide against Tripterygium glycosides (TG)-induced liver injury and its mechanisms. J Toxicol Sci, 41:165-173.

[27] Li DZ (2008). Floristics and plant biogeography in China. J Integr Plant Biol, 50:771-7.

[28] Ying Liu. Pharmacognostic study of Zhizi [D]. Chengdu. Sichuan University, 2003. 
[29] Liu H, Chen YF, Li F, Zhang HY (2013). Fructus Gardenia (Gardenia jasminoides J. Ellis) phytochemistry, pharmacology of cardiovascular, and safety with the perspective of new drugs development. J Asian Nat Prod Res, 15:94-110.

[30] Akao T, Kobashi K, Aburada M (1994). Enzymic studies on the animal and intestinal bacterial metabolism of geniposide. Biol Pharm Bull, 17:157376.

[31] Feng Q, Cao HL, Xu W, Li XR, Ren YQ, Du LF (2011). Apoptosis induced by genipin in human leukemia K562 cells: involvement of c-Jun N-terminal kinase in $\mathrm{G}(2) / \mathrm{M}$ arrest. Acta Pharmacol Sin, 32:519-27.

[32] Sung HW, Chang Y, Liang IL, Chang WH, Chen YC (2000). Fixation of biological tissues with a naturally occurring crosslinking agent: fixation rate and effects of $\mathrm{pH}$, temperature, and initial fixative concentration. J Biomed Mater Res, 52:77-87.

[33] Gutheil WG, Reed G, Ray A, Anant S, Dhar A (2012). Crocetin: an agent derived from saffron for prevention and therapy for cancer. Curr Pharm Biotechnol, 13:1739.

[34] Alavizadeh SH and Hosseinzadeh H (2014). Bioactivity assessment and toxicity of crocin: a comprehensive review. Food Chem Toxicol, 64:65-80.

[35] Tang K, Guo D, Zhang L, Guo J, Zheng F, Si J, et al. (2016). Immunomodulatory effects of Longdan Xiegan Tang on $\mathrm{CD}^{+} / \mathrm{CD}^{+} \mathrm{T}$ cells and associated inflammatory cytokines in rats with experimental autoimmune uveitis. Mol Med Rep, 14:2746-54.

[36] Wang X, Sun W, Sun H, Lv H, Wu Z, Wang P, et al. (2008). Analysis of the constituents in the rat plasma after oral administration of Yin Chen Hao Tang by UPLC/Q-TOF-MS/MS. J Pharm Biomed Anal, 46:4770.

[37] Tang H, Min G, Ge B, Li Y, Liu X, Jiang S (2008). Evaluation of protective effects of Chi-Zhi-Huang decoction on Phase I drug metabolism of liver injured rats by cocktail probe drugs. J Ethnopharmacol, 117:420-6.

[38] Ma ZT, Yang XW, Zhang Y, Liu JX (2014). Pharmacochemistry and integrated pharmacokinetics of six alkaloids after oral administration of huang-lian-jiedu-tang decoction. J Asian Nat Prod Res, 16:483-96.

[39] Wang J, Li PT, Du H, Hou JC, Li WH, Pan YS, et al. (2012). Tong Luo Jiu Nao injection, a traditional Chinese medicinal preparation, inhibits MIP-1beta expression in brain microvascular endothelial cells injured by oxygen-glucose deprivation. J Ethnopharmacol, 141:151-7.

[40] Xu P, Du SY, Lu Y, Bai J, Guo YW, Du Q, et al. (2014). The effect of stroke and other components in Xing-NaoJing on the pharmacokinetics of geniposide. J Ethnopharmacol, 152:302-307.

[41] Li Y, Li L and Holscher C (2016). Therapeutic potential of Genipin in central neurodegenerative diseases. CNS Drugs, 30:889-97.

[42] Hou YC, Tsai SY, Lai PY, Chen YS, Chao PD (2008). Metabolism and pharmacokinetics of genipin and geniposide in rats. Food Chem Toxicol, 46:2764-9.
[43] Pan L, Wang W, Shi F, Zhou J, Zhang M, Zhu H, et al. (2013). Exploratory pharmacokinetics of Geniposide in rat model of cerebral ischemia orally administered with or without baicalin and/or berberine. Evid Based Complement Alternat Med, 2013:349531.

[44] Lu Y, Du SY, Chen XL, Wu Q, Song X, Xu B, et al. (2011). Enhancing effect of natural borneol on the absorption of geniposide in rat via intranasal administration. J Zhejiang Univ Sci B, 12:143-8.

[45] Zhao C, Zhang H, Li H, Lv C, Liu X, Li Z, et al. (2017). Geniposide ameliorates cognitive deficits by attenuating the cholinergic defect and amyloidosis in middle-aged Alzheimer model mice. Neuropharmacology, 116:18-29.

[46] Lv C, Wang L, Liu X, Yan S, Yan SS, Wang Y, et al. (2015). Multi-faced neuroprotective effects of geniposide depending on the RAGE-mediated signaling in an Alzheimer mouse model. Neuropharmacology, 89:175-184.

[47] Zhang H, Zhao C, Lv C, Liu X, Du S, Li Z, et al. (2016). Geniposide alleviates amyloid-induced synaptic injury by protecting axonal mitochondrial trafficking. Front Cell Neurosci, 10:309.

[48] Liu Z, Zhang Y, Liu J, Yin F (2017). Geniposide attenuates the level of Abeta1-42 via enhancing leptin signaling in cellular and APP/PS1 transgenic mice. Arch Pharm Res, 40:571-8.

[49] Zhao C, Lv C, Li H, Du S, Liu X, Li Z, et al. (2016). Geniposide protects primary cortical neurons against oligomeric Abeta1-42-Induced neurotoxicity through a mitochondrial pathway. PLoS One, 11: e0152551.

[50] Zhang Y, Yin F, Liu J, Liu Z (2016). Geniposide attenuates the phosphorylation of Tau protein in cellular and insulin-deficient APP/PS1 transgenic mouse model of Alzheimer's disease. Chem Biol Drug Des, 87:40918.

[51] Chen Y, Zhang Y, Li L, Holscher C (2015). Neuroprotective effects of geniposide in the MPTP mouse model of Parkinson's disease. Eur J Pharmacol, 768:21-7.

[52] Su C, Yang X, Lou J (2016). Geniposide reduces alphasynuclein by blocking microRNA-21/lysosomeassociated membrane protein $2 \mathrm{~A}$ interaction in Parkinson disease models. Brain Res, 1644:98-106.

[53] Liao P, Liu L, Wang B, Li W, Fang X, Guan S (2014). Baicalin and geniposide attenuate atherosclerosis involving lipids regulation and immunoregulation in ApoE-/- mice. Eur J Pharmacol, 740:488-95.

[54] Liu L, Liao P, Wang B, Fang X, Li W, Guan S (2014). Oral administration of baicalin and geniposide induces regression of atherosclerosis via inhibiting dendritic cells in ApoE-knockout mice. Int Immunopharmacol, 20:197-204.

[55] Wang B, Liao PP, Liu LH, Fang X, Li W, Guan SM (2016). Baicalin and geniposide inhibit the development of atherosclerosis by increasing Wnt 1 and inhibiting dickkopf-related protein-1 expression. J Geriatr Cardiol, 13:846-54.

[56] Yu D, Shi M, Bao J, Yu X, Li Y, Liu W (2016). Genipin ameliorates hypertension-induced renal damage via the 
angiotensin II-TLR/MyD88/MAPK pathway. Fitoterapia, 112:244-53.

[57] Ma ZG, Dai J, Zhang WB, Yuan Y, Liao HH, Zhang N, et al. (2016). Protection against cardiac hypertrophy by geniposide involves the GLP-1 receptor / AMPKalpha signalling pathway. Br J Pharmacol, 173:1502-16.

[58] Gao Y, Chen ZY, Liang X, Xie C, Chen YF (2015). Anti-atherosclerotic effect of geniposidic acid in a rabbit model and related cellular mechanisms. Pharm Biol, 53:280-5.

[59] Jiang F, Jiang R, Zhu X, Zhang X, Zhan Z (2013). Genipin inhibits TNF-alpha-induced vascular smooth muscle cell proliferation and migration via induction of HO-1. PLoS One, 8: e74826.

[60] Zhang HY, Liu H, Yang M, Wei SF (2013). Antithrombotic activities of aqueous extract from Gardenia jasminoides and its main constituent. Pharm Biol, 51:221-5.

[61] Liu HT, He JL, Li WM, Yang Z, Wang YX, Yin J, et al. (2010). Geniposide inhibits interleukin-6 and interleukin-8 production in lipopolysaccharide-induced human umbilical vein endothelial cells by blocking p38 and ERK1/2 signaling pathways. Inflamm Res, 59:45161 .

[62] Zhang H, Lai Q, Li Y, Liu Y, Yang M (2017). Learning and memory improvement and neuroprotection of Gardenia jasminoides (Fructus gardenia) extract on ischemic brain injury rats. J Ethnopharmacol, 196:22535.

[63] Li F, Li W, Li X, Li F, Zhang L, Wang B, et al. (2016). Geniposide attenuates inflammatory response by suppressing P2Y14 receptor and downstream ERK1/2 signaling pathway in oxygen and glucose deprivationinduced brain microvascular endothelial cells. J Ethnopharmacol, 185:77-86.

[64] Wang J, Hou J, Zhang P, Li D, Zhang C, Liu J (2012). Geniposide reduces inflammatory responses of oxygenglucose deprived rat microglial cells via inhibition of the TLR4 signaling pathway. Neurochem Res, 37:223548.

[65] Liu J, Zhou CX, Zhang ZJ, Wang LY, Jing ZW, Wang $Z$ (2012). Synergistic mechanism of gene expression and pathways between jasminoidin and ursodeoxycholic acid in treating focal cerebral ischemia-reperfusion injury. CNS Neurosci Ther, 18:674-82.

[66] Lee P, Lee J, Choi SY, Lee SE, Lee S, Son D (2006). Geniposide from Gardenia jasminoides attenuates neuronal cell death in oxygen and glucose deprivationexposed rat hippocampal slice culture. Biol Pharm Bull, 29:174-6.

[67] Dai MM, Wu H, Li H, Chen J, Chen JY, Hu SL, et al. (2014). Effects and mechanisms of Geniposide on rats with adjuvant arthritis. Int Immunopharmacol, 20:4653.

[68] Wang R, Wu H, Chen J, Li SP, Dai L, Zhang ZR, et al. (2017). Antiinflammation effects and mechanisms study of Geniposide on rats with collagen-induced arthritis. Phytother Res, 31:631-7.
[69] Ling Zhao. Metabolomic study of Huanglian Jiedu decoction as an effective prophylactic treatment for rheumatoid arthritis [D]. Jilin Agricultural University. Changchun. 2012.

[70] Lee CH, Kwak SC, Kim JY, Oh HM, Rho MC, Yoon $\mathrm{KH}$, et al. (2014). Genipin inhibits RANKL-induced osteoclast differentiation through proteasome-mediated degradation of c-Fos protein and suppression of NFkappaB activation. J Pharmacol Sci, 124:344-53.

[71] Chen QC, Zhang WY, Kim H, Lee IS, Ding Y, Youn UJ, et al. (2010). Effects of Gardeniae Fructus extract and geniposide on promoting ligament cell proliferation and collagen synthesis. Phytother Res, 24 Suppl 1:S15.

[72] Chen QC, Zhang WY, Youn U, Kim H, Lee I, Jung HJ, et al. (2009). Iridoid glycosides from Gardeniae Fructus for treatment of ankle sprain. Phytochemistry, 70:77984.

[73] Guan L, Feng H, Gong D, Zhao X, Cai L, Wu Q, et al. (2013). Genipin ameliorates age-related insulin resistance through inhibiting hepatic oxidative stress and mitochondrial dysfunction. Exp Gerontol, 48:138794.

[74] Bauge C, Girard N, Lhuissier E, Bazille C, Boumediene K (2014). Regulation and Role of TGFbeta Signaling Pathway in Aging and Osteoarthritis Joints. Aging Dis, 5:394-405.

[75] McGann ME, Bonitsky CM, Jackson ML, Ovaert TC, Trippel SB, Wagner DR (2015). Genipin crosslinking of cartilage enhances resistance to biochemical degradation and mechanical wear. J Orthop Res, 33:1571-9.

[76] Hoshovs'ka Iu V, Korkach Iu P, Shymans'ka TV, Kotsiuruba AV, Sahach VF (2009). [Effects of uncoupling proteins on nitric oxide synthesis and oxidative stress development in ishemia-reperfusion of old rat hearts]. Fiziol Zh, 55:3-11.

[77] Dutta D, Calvani R, Bernabei R, Leeuwenburgh C, Marzetti E (2012). Contribution of impaired mitochondrial autophagy to cardiac aging: mechanisms and therapeutic opportunities. Circ Res, 110:1125-38.

[78] Li W, Li P, Liu Z, Du Q, Steinmetz A, Wang N, et al. (2014). A Chinese medicine preparation induces neuroprotection by regulating paracrine signaling of brain microvascular endothelial cells. J Ethnopharmacol, 151:686-93.

[79] Hekimi S (2006). How genetic analysis tests theories of animal aging. Nat Genet, 38:985-91.

[80] Chae SY, Park SY, Park JO, Lee KJ, Park G (2016). Gardenia jasminoides extract-capped gold nanoparticles reverse hydrogen peroxide-induced premature senescence. J Photochem Photobiol B, 164:204-11.

[81] Liu JH, Yin F, Guo LX, Deng XH, Hu YH (2009). Neuroprotection of geniposide against hydrogen peroxide induced PC12 cells injury: involvement of PI3 kinase signal pathway. Acta Pharmacol Sin, 30:159-65.

[82] Lee MJ, Hsu JD, Wang CJ (1995). Inhibition of 12-Otetradecanoylphorbol-13-acetate-caused tumor 
promotion in benzo[a]pyrene-initiated CD-1 mouse skin by geniposide. Anticancer Res, 15:411-6.

[83] Song X, Zhang W, Wang T, Jiang H, Zhang Z, Fu Y, et al. (2014). Geniposide plays an anti-inflammatory role via regulating TLR4 and downstream signaling pathways in lipopolysaccharide-induced mastitis in mice. Inflammation, 37:1588-98.

[84] Chen S, Zhao X, Sun P, Qian J, Shi Y, Wang R (2017). Preventive effect of Gardenia jasminoides on $\mathrm{HCl} /$ ethanol induced gastric injury in mice. J Pharmacol Sci, 133:1-8.

[85] Zhang G, He JL, Xie XY, Yu C (2012). LPS-induced iNOS expression in N9 microglial cells is suppressed by geniposide via ERK, p38 and nuclear factor-kappaB signaling pathways. Int J Mol Med, 30:561-8.

[86] Xu B, Li YL, Xu M, Yu CC, Lian MQ, Tang ZY, et al. (2017). Geniposide ameliorates TNBS-induced experimental colitis in rats via reducing inflammatory cytokine release and restoring impaired intestinal barrier function. Acta Pharmacol Sin, 38:688-98.

[87] Kim BC, Kim HG, Lee SA, Lim S, Park EH, Kim SJ, et al. (2005). Genipin-induced apoptosis in hepatoma cells is mediated by reactive oxygen species/c-Jun NH2-terminal kinase-dependent activation of mitochondrial pathway. Biochem Pharmacol, 70:13981407.

[88] Cao H, Feng Q, Xu W, Li X, Kang Z, Ren Y, et al. (2010). Genipin induced apoptosis associated with activation of the c-Jun NH2-terminal kinase and p53 protein in HeLa cells. Biol Pharm Bull, 33:1343-8.

[89] Guo LX, Liu JH, Zheng XX, Yin ZY, Kosaraju J, Tam KY (2017). Geniposide improves insulin production and reduces apoptosis in high glucose-induced glucotoxic insulinoma cells. Eur J Pharm Sci, In Press.

[90] Li R, Cai L, Tang WJ, Lei C, Hu CM, Yu F (2016). Apoptotic Effect of Geniposide on Fibroblast-Like Synoviocytes in Rats with Adjuvant-Induced Arthritis via Inhibiting ERK Signal Pathway In Vitro. Inflammation, 39:30-8.

[91] Liu J, Yin F, Xiao H, Guo L, Gao X (2012). Glucagonlike peptide 1 receptor plays an essential role in geniposide attenuating lipotoxicity-induced beta-cell apoptosis. Toxicol In Vitro, 26:1093-7.
Peng CH, Tseng TH, Huang CN, Hsu SP, Wang CJ (2005). Apoptosis induced by penta-acetyl geniposide in C6 glioma cells is associated with JNK activation and Fas ligand induction. Toxicol Appl Pharmacol, 202:172-9.

[93] Peng CH, Tseng TH, Liu JY, Hsieh YH, Huang CN, Hsu SP, et al. (2004). Penta-acetyl geniposide-induced C6 glioma cell apoptosis was associated with the activation of protein kinase C-delta. Chem Biol Interact, 147:287-96.

[94] Liu J, Zhang Y, Deng X, Yin F (2013). Geniposide decreases the level of Abeta1-42 in the hippocampus of streptozotocin-induced diabetic rats. Acta Biochim Biophys Sin (Shanghai), 45:787-91.

[95] Chen YI, Cheng YW, Tzeng CY, Lee YC, Chang YN, Lee SC, et al. (2014). Peroxisome proliferator-activated receptor activating hypoglycemic effect of Gardenia jasminoides Ellis aqueous extract and improvement of insulin sensitivity in steroid induced insulin resistant rats. BMC Complement Altern Med, 14:30.

[96] Kojima K, Shimada T, Nagareda Y, Watanabe M, Ishizaki J, Sai Y, et al. (2011). Preventive effect of geniposide on metabolic disease status in spontaneously obese type 2 diabetic mice and free fatty acid-treated HepG2 cells. Biol Pharm Bull, 34:1613-18.

[97] Guo L, Zheng X, Liu J, Yin Z (2016). Geniposide suppresses hepatic glucose production via AMPK in HepG2 cells. Biol Pharm Bull, 39:484-41.

[98] Wang GF, Wu SY, Xu W, Jin H, Zhu ZG, Li ZH, et al. (2010). Geniposide inhibits high glucose-induced cell adhesion through the NF-kappaB signaling pathway in human umbilical vein endothelial cells. Acta Pharmacol Sin, 31:953-62.

[99] Shin JS and Huh YS (2014). Effect of intake of gardenia fruits and combined exercise of middle-aged obese women on hormones regulating energy metabolism. $\mathbf{J}$ Exerc Nutrition Biochem, 18:41-9.

[100] Chen YH, Lan T, Li J, Qiu CH, Wu T, Gou HJ, et al. (2012). Gardenia jasminoides attenuates hepatocellular injury and fibrosis in bile duct-ligated rats and human hepatic stellate cells. World J Gastroenterol, 18:715865. 